This item was submitted to Loughborough's Research Repository by the author.

Items in Figshare are protected by copyright, with all rights reserved, unless otherwise indicated.

\title{
In situ colorimetric and composite coloration efficiency measurements for electrochromic Prussian blue
}

PLEASE CITE THE PUBLISHED VERSION

PUBLISHER

(C) Royal Society of Chemistry

LICENCE

CC BY-NC-ND 4.0

\section{REPOSITORY RECORD}

Mortimer, Roger J., and John R. Reynolds. 2019. "In Situ Colorimetric and Composite Coloration Efficiency Measurements for Electrochromic Prussian Blue”. figshare. https://hdl.handle.net/2134/1045. 
This item was submitted to Loughborough's Institutional Repository by the author and is made available under the following Creative Commons Licence conditions.

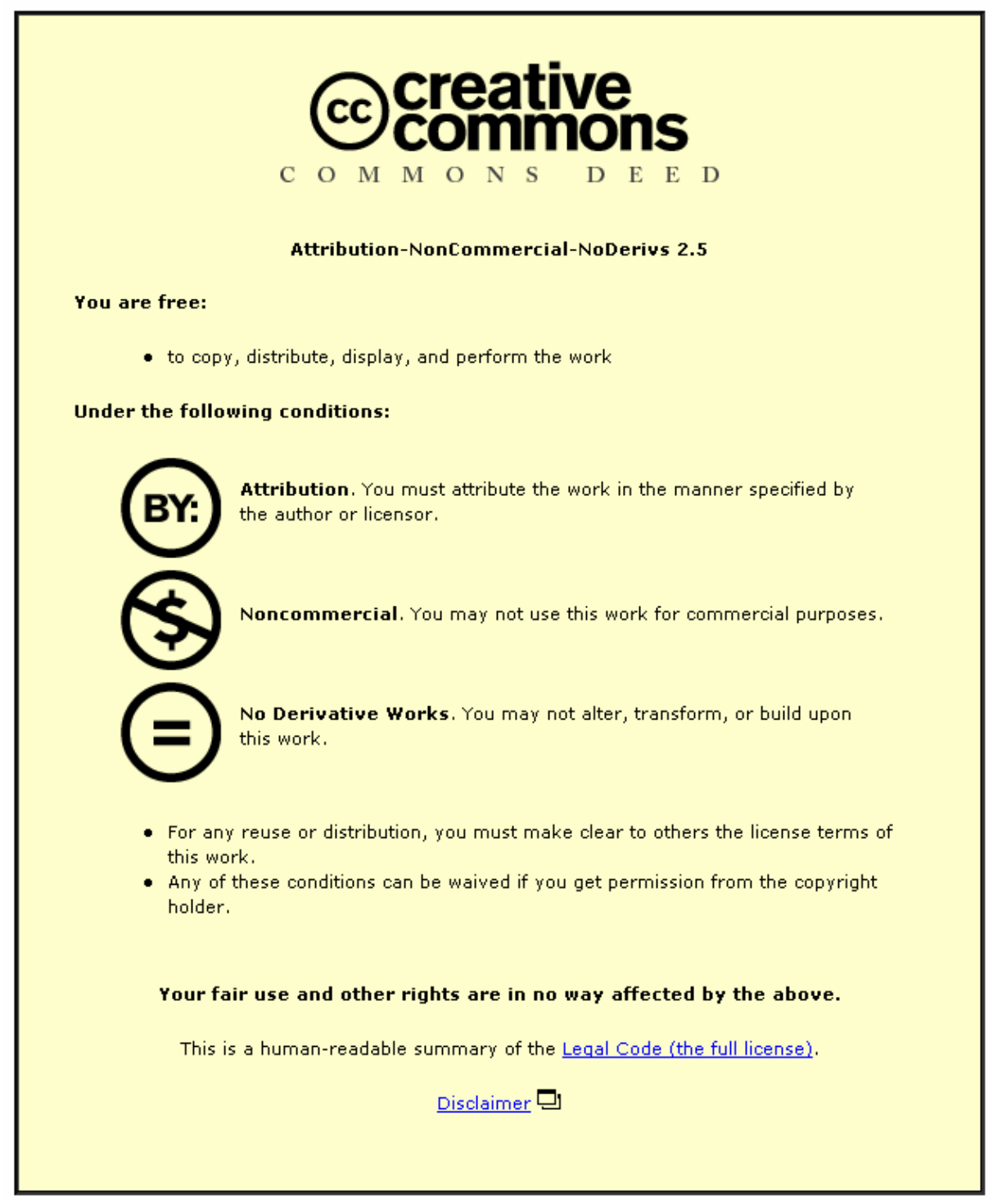

For the full text of this licence, please go to: http://creativecommons.org/licenses/by-nc-nd/2.5/ 
This article has been submitted to

Loughborough

University's

Institutional

Repository by the

author.

Author for proofs and correspondence: Dr R J Mortimer, Department of Chemistry, Loughborough University, Loughborough, Leicestershire, LE11 3JU, UK.

\section{In situ colorimetric and composite coloration efficiency}

\section{measurements for electrochromic Prussian blue}

Roger J. Mortimer* and John R. Reynolds

The George and Josephine Butler Polymer Research Laboratory, Department of

Chemistry, Center for Macromolecular Sciences and Engineering, University of Florida, Gainesville, Florida 32611, USA

An in situ colorimetric method, based on the CIE (Commission Internationale de l'Eclairge) system of colorimetry, has been successfully applied to the study of electrochromism in electrochemically deposited films of Prussian blue (iron(III) hexacyanoferrate(II), PB) on transmissive ITO/glass substrates for the first time. On electrochemical reduction of PB to Prussian white (iron(II) hexacyanoferrate(II), PW), sharp and reversible changes in the hue and saturation occur, as shown by the track of the CIE $1931 x y$ chromaticity coordinates. For PB, the CIELAB 1976 colour space coordinates were $L^{*}=73, a^{*}=-26$ and $b^{*}=-33$, with a dominant wavelength calculated as $488 \mathrm{~nm}$. Concurrently, as the intensely absorbing PB mixed-valence chromophore is 'bleached' to the transparent PW, a large increase in the relative luminance of the electrochromic film is observed. On oxidation of PB, the CIELAB 1976 colour space

\footnotetext{
† Permanent address: Dr R J Mortimer, Department of Chemistry, Loughborough University, Loughborough, Leicestershire, LE11 3JU, UK. E-mail: R.J.Mortimer@lboro.ac.uk
} 
coordinates show the transition through intermediate green to the Prussian yellow (iron(III) hexacyanoferrate(III), PY) state $\left(L^{*}=94, a^{*}=2\right.$ and $\left.b^{*}=18\right)$, with a steady increase in relative luminance. To reliably compare the power requirement of PB films with other electrochromic systems, composite coloration efficiencies (CCE's) have been calculated, using a tandem chronoabsorptometry/chronocoulometry method, as previously developed for organic polymer systems. Using 95\% of the total transmittance change at $\lambda_{\max }$ as reference point, coloration efficiencies, $\eta=\Delta A\left(\lambda_{\max }\right) / \mathrm{Q}$, were calculated as 143 and $150 \mathrm{~cm}^{2} \mathrm{C}^{-1}$ respectively for the $\mathrm{PB} / \mathrm{PW}$ and $\mathrm{PW} / \mathrm{PB}$ electrochromic transitions.

\section{Introduction}

Throughout its 300 year history, ${ }^{1}$ the mixed-valence complex Prussian blue (iron(III) hexacyanoferrate(II), PB), has been extensively used as a pigment in the formulation of paints, lacquers, and printing inks. ${ }^{2,3} \quad \mathrm{~PB}$ and numerous other metal hexacyanometallates, ${ }^{4,5}$ can be deposited onto inert electrode substrates to give redoxactive films ${ }^{6}$ that have electrochromic, ${ }^{5,7}$ electrocatalytic ${ }^{5,8,9}$ and electroanalytical applications. ${ }^{10,11,12}$

PB films exhibit four-colour polyelectrochromicity. ${ }^{13,14}$ Electrochemical reduction of PB produces Prussian white (iron(II) hexacyanoferrate(II), PW), which appears transparent as a thin film. Oxidation of PB yields Prussian yellow (iron(III) hexacyanoferrate(III), PY), via the intermediate Prussian green (PG). Early PB-based electrochromic devices (ECD's) employed PB as the sole electrochromic material. Examples include a seven-segment display using PB-modified optically transparent 
electrodes, ${ }^{15}$ a solid-state system ${ }^{16,17}$ where a PB-containing Nafion ${ }^{\circledR}$ composite film was sandwiched between the two indium-doped tin oxide (ITO)/glass substrates, and an ECD that utilised a single film of PB, without addition of a conventional electrolyte. ${ }^{18}$ The blue-transparent (anodically-colouring) transition in PB at one electrode has also been combined with cathodically-colouring electrochromic materials at the second electrode, in 'complementary' ECD's, where both films are coloured simultaneously. Examples include PB/tungsten oxide, ${ }^{19,20,21,22,23} \mathrm{~PB} /$ polyaniline, ${ }^{24,25,26,27,28,29,30}$ and PB/ytterbium bis(phthalocyanine) $\left(p p-\mathrm{Yb}(\mathrm{Pc})_{2}\right)^{31}$ devices. More recently, ${ }^{32}$ an ECD based on the assembly of $\mathrm{PB} / \mathrm{ITO} /$ glass and poly(3,4-ethylenedioxythiophene) (PEDOT)/ITO/glass substrates with a poly(methyl methacrylate) (PMMA)-based gel polymer electrolyte, has been described.

In this paper, we describe the application of new methods ${ }^{33,34}$ to the quantitative measurement of colour in electrochromic PB films. In electrochromism, such measurements have previously been applied only to conducting polymer systems and will be of value for the optimisation of PB-based ECD performance parameters. Colour is a very subjective phenomenon, causing the description of colour difference or the comparison of two colours to be quite difficult. However, much effort has been given to the development of colorimetric analysis, which allows a quantitative description of colour and relative transmissivity as sensed by the human eye. Colorimetry provides a more precise way to define colour than spectrophotometry. ${ }^{35}$ Rather than measure absorption bands, in colorimetry the human eye's sensitivity to light across the visible region is measured and a numerical description of colour is given. Since the recent report $^{33}$ of a simple in situ colorimetric analysis method for the precise control and 
measurement of colour in electrochromic systems, this approach is currently in vogue for the characterisation of electrochromic conductive polymer films and devices. ${ }^{36,37,38,39,40,41}$ Here we report the application of in situ colorimetric analysis to the precise mapping of colour in electrochromic PB films in transmission mode. Earlier colorimetric analysis for inorganic electrochromic systems has been restricted to measurements on tungsten oxide films, using complicated electronic instrumentation. ${ }^{42,43,44}$ We anticipate that the simple approach employed here, with use of a commercial Chroma Meter, will be of interest for the colorimetric characterisation of a wide range of inorganic electrochromic systems.

In addition to colorimetric analysis, coloration efficiency (CE) measurements are a useful tool in the study of electrochromism. ${ }^{45} \mathrm{CE}, \eta\left(\mathrm{cm}^{2} \mathrm{C}^{-1}\right)$, is defined as the ratio of the change in absorbance, $\Delta A$, at a specified wavelength, to the injected/ejected charge per unit electrode area. The ideal electrochromic material or device would exhibit a large absorbance change with a small amount of charge, giving rise to a high CE. As has been recently pointed out, ${ }^{34}$ although the analysis of CE is important, the methods utilised to measure it have varied between research groups and this can lead to difficulties in comparisons between different electrochromic materials. A general method for measuring electrochromic conductive polymer composite coloration efficiencies (CCE’s) effectively and consistently has been proposed. ${ }^{34}$ We now show the application of this tandem chronocoulometry/chronoabsorptometry method to electrochromic PB films. 


\section{Experimental}

\section{Materials}

Anhydrous iron(III) chloride $\left(\mathrm{FeCl}_{3}\right)$, potassium hexacyanoferrate(III) $\left(\mathrm{K}_{3} \mathrm{Fe}(\mathrm{CN})_{6}\right)$, and potassium chloride $(\mathrm{KCl})$ were certified ACS grade from Fisher and used without further purification. Electrode substrates were tin-doped indium oxide (ITO) on glass ( 7 x 50 x $0.7 \mathrm{~mm}$, unpolished float glass, $\mathrm{SiO}_{2}$ passivated, 8-12 $\Omega / \square$, part no. CG-50IN-CUV) from Delta Technologies Ltd..

\section{Electrochemical measurements}

Electrochemical measurements were carried out in de-oxygenated solutions using an EG\&G Model PAR273A potentiostat/galvanostat, under the control of Scribner and Associates Corrware II software. No iR compensation was employed.

\section{Prussian blue deposition}

ITO/glass substrates were pre-treated, in order to remove any trace of adhesive/impurities on the surface, by sonication (3 minutes) in a $1 \mathrm{M}$ hydrochloric acid solution followed by rinsing with deionised water. Immediately prior to electrochemical deposition of PB, the ITO/glass substrates were rinsed in acetone and air dried. For the electrochemical deposition of $\mathrm{PB}$, a standard $1 \mathrm{~cm}$ quartz cuvette was used as electrochemical cell. A machined polytetrafluoroethylene lid allowed the ITO/glass working electrode to be mounted transverse to the optical face of the cuvette. Additional holes in the lid allowed a coiled platinum wire counter electrode and silver/silver chloride wire reference 
electrode to be positioned in the electrolyte solution. With aqueous $0.2 \mathrm{M} \mathrm{KCl}$ as supporting electrolyte in all solutions, this reference electrode maintained a stable potential of $+0.067 \mathrm{~V} v s$. a commercial BAS silver/silver chloride/saturated potassium chloride (+0.197 V vs. SHE) reference electrode. For all measurements, the lower $40 \mathrm{~mm}$ of each ITO/glass working electrode was immersed in solution, providing a submerged geometric electrode area of $2.80 \mathrm{~cm}^{2}$. PB films, corresponding to an electrodeposition charge density of $6.3 \mathrm{mC} \mathrm{cm}{ }^{-2}$ and a film thickness of $320 \mathrm{~nm},{ }^{46}$ were potentiostatically deposited at $+0.50 \mathrm{~V}$ ( $v s$. Ag/AgCl wire) for $300 \mathrm{~s}$ in an aqueous solution of $5 \mathrm{mM}$ $\mathrm{FeCl}_{3}, 5 \mathrm{mM} \mathrm{K}_{3} \mathrm{Fe}(\mathrm{CN})_{6}$ and $0.2 \mathrm{M} \mathrm{KCl}$. PB film charge densities were coulometrically determined from the integrated current for electrochemical reduction to Prussian white, on potential stepping from +0.50 to $-0.20 \mathrm{~V}$ vs. $\mathrm{Ag} / \mathrm{AgCl}$ wire, in $0.2 \mathrm{M} \mathrm{KCl}$ solution. As-deposited $\mathrm{Fe}^{3+}$-counterion containing 'insoluble' $\mathrm{PB}$ films were converted to the $\left[\left(\mathrm{K}^{+}\right)_{1 / 3}\left(\mathrm{Fe}^{2+}\right)_{1 / 3} \mathrm{Fe}^{\mathrm{III}} \mathrm{Fe}^{\mathrm{II}}(\mathrm{CN})_{6}\right]$ form, ${ }^{47,48}$ by 10 reductive potential cycles, $50 \mathrm{mV} \mathrm{s}{ }^{-1}$, $+0.50 \mathrm{~V}$ to $-0.20 \mathrm{~V}$, in $0.2 \mathrm{M} \mathrm{KCl}$.

\section{Spectroscopic measurements}

Visible/NIR region absorption spectra (350 - $1400 \mathrm{~nm}$ ) and chronoabsorptometry data (at the PB $\left.\lambda_{\max }(686 \mathrm{~nm})\right)$ were recorded in situ in transmission using a Varian Cary 500 Scan UV-vis-NIR spectrophotometer. An identical quartz cuvette, with a mounted clean ITO/glass substrate in $0.2 \mathrm{M} \mathrm{KCl}$ was employed in the reference beam. 


\section{Colorimetry}

Colorimetry measurements were obtained, under potentiostatic control at a series of potentials, by use of a Minolta CS-100 Chroma Meter and CIE recommended normal/normal $(0 / 0)$ illuminating/viewing geometry for transmittance measurements. ${ }^{49}$ The calibration was set to the preset mode. Samples were illuminated by a $\mathrm{D}_{50}(5000 \mathrm{~K})$ constant temperature daylight simulating light source in a light booth specially designed to exclude external light. To ensure equilibrium readings, colour coordinates ( $Y, x$, and $y$ values) were recorded after each potential had been applied for 50 seconds and the current had decayed to background levels. Additional readings were taken at 60 seconds, to ensure the colour coordinates had stabilised. A background measurement was taken under identical conditions, using a blank ITO/glass substrate in a $0.2 \mathrm{M} \mathrm{KCl}$ electrolyte solution held in a standard quartz cuvette. For all measurements, the ITO/glass substrate was on the side of the cuvette closest to the Chroma Meter, with the conductive side facing the light source. The $Y x y$ values of the standard illuminant were measured and converted to $X_{n}, Y_{n}, Z_{n}$ tristimulus values. ${ }^{35}$ These tristimulus values were used with the calculated tristimulus values $(X, Y, Z)$ of the sample for conversion to CIELAB $L^{*} a^{*} b^{*}$ coordinates. $x$ and $y$ coordinates were calculated from the $X Y Z$ tristimulus values using the formulae, $x=X /(X+Y+Z)$ and $y=Y /(X+Y+Z)$.

\section{Results and discussion}

There are three attributes that are used to describe colour. The first identifies a colour by its location in the spectral sequence, i.e., what wavelength is associated with this colour. This is known as the hue, dominant wavelength, or chromatic colour, and is the 
wavelength where maximum contrast occurs. It is this aspect which is commonly, but mistakenly, referred to as colour. The second attribute, relating to the level of white and/or black, is known as saturation, chroma, tone, intensity, or purity. The third attribute is the brightness of the colour, also referred to as value, lightness, or luminance. Luminance is very informative in considering the properties of cathodically or anodically colouring electrochromic materials, because, with only one value, it provides information about the perceived transparency of a sample over the entire visible range. For the PB system it will be very useful to have knowledge of these three colour attributes for the design and optimisation of ECD's that employ PB as one or both of the electrochromic materials. Furthermore, precise knowledge of the PB coloration efficiency will establish whether its power requirement is appropriate for a given application.

\section{Colorimetric analysis for the $\mathrm{PB} / \mathrm{PW}$ electrochromic transition}

PB films were potentiostatically deposited onto ITO/glass substrates by electroreduction of solutions containing iron(III) and hexacyanoferrate(III) ions. Reduction of the solution-phase adduct iron(III)hexacyanoferrate(III), present in equilibrium with the ions, is the principal electron transfer process in PB electrodeposition. ${ }^{13}$ The electrochemical deposition time and solution concentrations were established as optimal in terms of the stability of the films, and the contrast of the visually-observed colour changes. ${ }^{13,14}$

Fig. 1 shows the well-established cyclic voltammogram (CV) for the PB to PW transition, with spectra for each of these states being shown in Fig. 2. 
Fig. 1 See end

Fig. 2 See end

Fig. 3 shows the hue and saturation track in the $x y$ chromaticity diagram for the PB to PW transition, as the potential is slowly stepped between +0.50 and -0.20 V. Fig. 4 is the $x y$ chromaticity diagram for the reverse process.

Fig. 3 See end

Fig. 4 See end

Although the $x y$ chromaticity diagram is not a uniform colour space, abrupt changes in colour are found to correspond with significant changes in the $x y$ coordinates. The large changes in $x y$ coordinates in Fig. 3 occur as the intensely absorbing mixed-valence $\mathrm{Fe}^{3+}\left[\mathrm{Fe}^{\mathrm{II}}(\mathrm{CN})_{6}\right]^{4-}$ blue chromophore is lost on reduction to PW. The reversibility of this process is seen on comparison with data in Fig. 4. The chromaticity coordinates lack the hysteresis that is seen on switching of electrochromic conducting polymer films between conductive and insulating forms. ${ }^{50}$ In Figs. 3(b) and 4(b), the data are overlaid onto the CIE (Commission Internationale de l'Eclairge) 1931 colour space template, showing the track of the $x y$ coordinates between the blue and white (transparent) colour states. In this representation, the line surrounding the horse-shoe shaped area is called the spectral locus, giving the visible light wavelengths. The most saturated colours lie along the 
spectral locus. The line connecting the longest and shortest wavelength contains the nonspectral purples and is known as the purple line. Surrounded by the spectral locus and the purple line is the region known as the colour locus, which contains every colour that can exist. For the PB/PW system, the PW state is confirmed as colourless, because the coordinates are coincident with those of the illumination source (the 'white point', where $x=0.358, y=0.385$ ). The location of any point in the $x y$ diagram gives the hue and saturation of the colour. The hue, measured as $488 \mathrm{~nm}$ for PB (see Figs. 3(b) and 4(b)), was determined by drawing a straight line through the white point and the point of interest to the spectral locus thus obtaining the dominant wavelength of the colour.

It is important to realise that the CIE does not associate a specific colour with any point on the $x y$ diagram. Colours cannot be specifically associated with a given pair of $x y$ coordinates, because the third dimension of colour, lightness, is not included in the diagram. The relative lightness or darkness of a colour is very important in how it is perceived, and is usually presented as the relative luminance, $Y$, of the sample, to that of the background, $Y_{0}$. Fig. 5 shows the variation of \% relative luminance with potential for the $\mathrm{PB} / \mathrm{PW}$ transition during both the 'bleaching' and colouring processes by potential stepping.

Fig. 5 See end

Relative luminance values can range from 100\% for white samples (no light absorbed) to zero for samples that absorb all the light. On PB reduction, the film luminance rapidly increases over a narrow potential range. That the luminance doesn't 
reach $100 \%$ is attributed to light scattering of the PW form. As for the $x y$ coordinate measurements, $Y$ values are coincident for the forward (reduction) (Fig. 5(a)) and reverse (oxidation) (Fig. 5(b)) directions of the PB/PW transition, with no hysteresis, showing the stability of the system. To obtain plots without hysteresis, preliminary measurements established the need to thoroughly de-oxygenate the $0.2 \mathrm{M} \mathrm{KCl}$ supporting electrolyte solution in the quartz cuvette. PW electrocatalytically reduces dissolved oxygen, ${ }^{51}$ leading to a significant $\mathrm{pH}$ increase during the substantial time periods that the $\mathrm{PB} / \mathrm{PW}$ system is held at reducing potentials during the colorimetric measurements. PB films are unstable in alkaline solutions, ${ }^{52}$ film dissolution giving the appearance of enhanced luminance of samples.

In Table 1 , the calculated $L * a * b *$ coordinates, a uniform colour space (CIELAB) defined by the CIE in 1976, are also shown at each applied potential. This representation further emphasises the narrow potential range for the PB/PW transition. The CIE $L^{*} a^{*} b^{*}$ space is a standard commonly used in the paint, plastic, and textile industries. $L^{*}$ is the lightness variable of the sample, while $a^{*}$ and $b^{*}$ correspond to the two antagonistic chromatic processes (red-green and yellow-blue). In the $L^{*} a^{*} b^{*}$ chromaticity diagram, + $a^{*}$ is the red direction, $-a^{*}$ is the green direction, $+b^{*}$ is the yellow direction, and $-b^{*}$ is the blue direction. The centre $(0,0)$ of the chromaticity diagram is achromatic; as the $a^{*}$ and $b^{*}$ values increase, the saturation of the colour increases. Comparison of the PB coordinates with those of the reduced form of tungsten oxide ${ }^{42,43,44}$ and the blue states of a range of different conducting polymer films ${ }^{33}$ show the distinct nature of the blue colour provided by PB. For example, the $L^{*} a * b *$ coordinates for the (deep blue) neutral form of PEDOT are 20, 15, and -43 respectively. ${ }^{33}$ 


\section{Colorimetric analysis for the PB/PY electrochromic transition}

As noted, PB is polyelectrochromic, oxidation yielding Prussian yellow (iron(III) hexacyanoferrate(III), PY), via the intermediate Prussian green (PG) state. However, PY is slightly soluble in water and for reason of stability, practical PB ECD’s have primarily exploited the PB/PW transition. This does not rule out the prospect of four-colour PB polyelectrochromic devices, as other solvent systems may not dissolve PY. Fig. 6 shows the full $\mathrm{CV}$ for $\mathrm{PB}$ on an ITO/glass substrate, to include the $\mathrm{PB} / \mathrm{PY}$ redox wave at positive potentials. Due to the dissolution of PY during the substantial time periods that the $\mathrm{PB} / \mathrm{PY}$ system is held at oxidising potentials during the colorimetric measurements, just a few measurements were recorded at a few specific potentials, as shown in Table 2. The colour coordinates at $+0.85 \mathrm{~V}$ and $+0.90 \mathrm{~V}$ correspond to intermediate green states, with the golden-yellow form being observed at $+1.10 \mathrm{~V}$ and above. The $L^{*} a^{*} b^{*}$ coordinates nicely show the changes that take place for the transition of blue through green to yellow. The $a^{*}$ coordinate moves from the negative (green) direction to close to zero. At the same time, the $b^{*}$ coordinate moves in a positive (yellow) direction, although the final value (18) shows the yellow saturation to be low. As expected, the oxidation of PB through PG to PY, led to an increase in luminance of the system (Table 2), although the film does not reach the luminance of the PW state.

\section{Composite coloration efficiency measurements for the PB/PW transition}

As noted above, the coloration efficiency, $\eta=\Delta A\left(\lambda_{\max }\right) / \mathrm{Q}$, is an efficient and practical tool for the measurement of power requirements of electrochromic materials. This 
concept has been used in studies for the comparison of different electrochromic materials. $^{34,40,45,53}$ We here show the application of the composite coloration efficiency measurements to the $\mathrm{PB} / \mathrm{PW}$ electrochromic transition. A tandem chronocoulometry/chronoabsorptometry method is used, with CCE's being calculated at specific percentage transmittance changes at the $\lambda_{\max }$ of the PB absorbance band.

Fig. 7(a) shows the dynamic measurement of the film absorbance at $686 \mathrm{~nm}$, during square-wave switching between $+0.50 \mathrm{~V}$ (PB, high absorbance) and $-0.20 \mathrm{~V}$ (PW, low absorbance). For the PB/PW transition, the electrochromic contrast at $686 \mathrm{~nm}$, calculated as $\Delta \% T$ from the maximum and minimum absorbance values was $60 \%$. This result is substantially higher than the percentage relative luminance change established in the colorimetric measurements $(46.5 \%$ from Table 1$)$. The difference nicely demonstrates the importance of relative luminance changes in providing more realistic contrast values since they offer a perspective on the transmissivity of a material as it relates to the human eye perception of transmittance over the entire visible region. ${ }^{54}$ Charge measurements, recorded simultaneously with the absorbance data are given in Fig. 7(b).

Fig. 7 See end

In the composite coloration efficiency method, to provide points of reference with which to compare the CCE values of various electrochromic materials, $\eta$ values are calculated at specific transmittance changes, as a percentage of the total $\Delta \% T(60 \%)$. Table 3 shows data for 90, 95 and 98\% changes, for both reduction of PB to PW, and 
oxidation of $\mathrm{PW}$ to $\mathrm{PB}$. Although the chronocoulometric data were corrected for background charging, as for measurements with conducting polymer films, ${ }^{34}$ the $\eta$ values for the reduction process are seen to slightly decrease with increase in optical change. This again shows that it is important to measure the charge passed at very specific transmittance values and not to simply divide the total absorbance change by the maximum charge passed. Here, this is important for reduction of PB to PW, because, as noted above, PW is a good catalyst for the reduction of oxygen, which may ingress into the cuvette at long measurement times. (It should be noted that in the original publication $^{34}$ that introduced composite coloration efficiency measurements, the calculated $\eta$ values were described as being at 90, 95 and 98\% of the total optical density change [ $\Delta \mathrm{OD}(=\Delta A)]$, at $\lambda_{\max }$. Considering the fundamental definition of $\Delta \mathrm{OD}$, this was a misstatement and all composite coloration efficiency calculations, here and previously, $^{34,53}$ were determined using the $\Delta \mathrm{OD}$ at 90,95 and $98 \%$ of the total transmittance $(\Delta \% T)$.

Although inorganic materials typically exhibit lower $\eta$ values than conducting polymers, it is of interest to note (Table 3) that the carefully measured values calculated here are comparable to those for films of PEDOT (at $150 \mathrm{~nm}$ film thickness), although switching times are longer for the $\mathrm{PB} / \mathrm{PW}$ transition. The $\eta$ values are similar for both reduction of $\mathrm{PB}$ to $\mathrm{PW}$, and oxidation of $\mathrm{PW}$ to $\mathrm{PB}$, although the switching times for the latter process are slightly shorter. To preserve the electroneutrality of the solid electrochromic film, potassium ion uptake/loss must accompany the colour-transforming electron-transfer. ${ }^{47,48}$ The difference in switching times is likely to relate to different rates of ingress/egress of potassium ions in the films. 


\section{Conclusion}

An in situ colorimetric method, based on the CIE (Commission Internationale de l'Eclairge) system of colorimetry, has been successfully applied to the study of electrochromic colour changes in electrochemically deposited films of Prussian blue on transmissive ITO/glass substrates. This technique is a convenient method for the precise measurement of the hue, saturation and luminance of colour states and allows the changes in these properties to be carefully monitored on redox switching between electrochromic colour states. This approach is frequently used in the study of electrochromic organic polymer films, and following the results described here, would clearly be applicable to other electrochromic systems, such as other metal hexacyanometallates, metal oxides, viologens, phthalocyanines and metallopolymers. Electrochromic materials have current and proposed device applications in both transmission (e.g., electrochromic sunglasses, 'smart' windows) and reflective (e.g., displays) modes. Due to the light source being behind the sample, the in situ colorimetry described here necessitates measurements to be made in transmissive mode. As we have found for spectral properties of electrochromic conductive polymers, ${ }^{39,55}$ we anticipate that the data would directly relate to both transmissive and reflective modes. As the field of electrochromism matures, the colorimetric method will be invaluable for the precise measurement, design and choice of specific colour states. In the construction of practical ECD's, a knowledge of electrical power requirements is also essential. The tandem chronocoulometry/chronoabsorptometry method, earlier introduced for the measurement of electrochromic conductive polymer composite coloration efficiencies, has been 
successfully applied here to Prussian blue, to allow reliable quantitative comparisons with other electrochromic systems.

\section{Acknowledgements}

We thank the EPSRC for an Overseas Travel Grant (GR/T23886/01) to RJM and the AFOSR (F49620-03-1-0091) for financial support. We acknowledge Aubrey L. Dyer for assistance with the artwork for the figures. 


\section{Graphical abstract}

CIE hue, saturation and luminance coordinates have been measured for the four electrochromic colour states of Prussian blue.

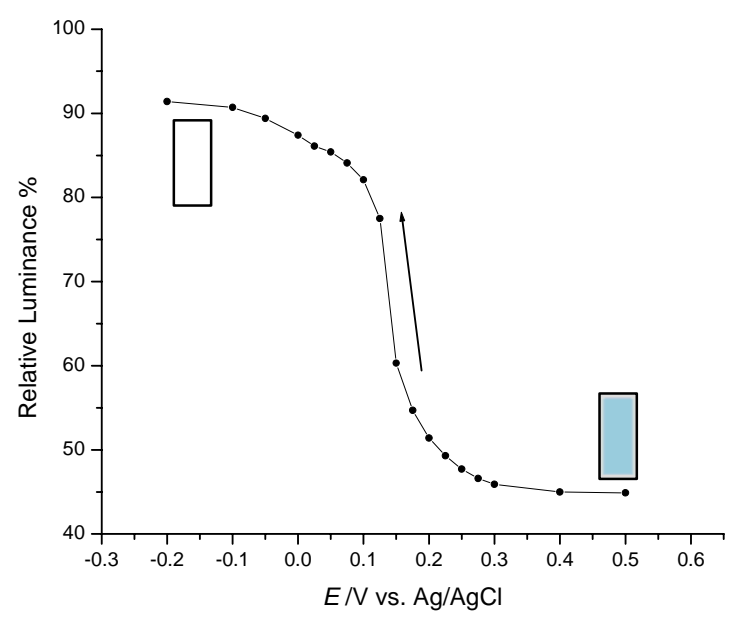


Table 1 Coordinates for reduction of PB to PW as a film on an ITO/glass substrate in aqueous $0.2 \mathrm{M} \mathrm{KCl}$ supporting electrolyte

\begin{tabular}{ccccccc}
\hline $\begin{array}{c}\boldsymbol{E} / \mathbf{V} \text { vs. } \\
\text { Ag/AgCl }\end{array}$ & $\mathbf{\%} \boldsymbol{Y}$ & $\boldsymbol{x}$ & $\boldsymbol{y}$ & $\boldsymbol{L}^{*}$ & $\boldsymbol{A}^{*}$ & $\boldsymbol{b}^{*}$ \\
\hline $\mathbf{0 . 5 0 0}$ & $\mathbf{4 4 . 9 \%}$ & $\mathbf{0 . 2 5 5}$ & $\mathbf{0 . 3 4 0}$ & $\mathbf{7 3}$ & $\mathbf{- 2 6}$ & -33 \\
0.400 & $45.0 \%$ & 0.255 & 0.340 & 73 & -26 & -33 \\
0.300 & $45.9 \%$ & 0.257 & 0.342 & 73 & -26 & -32 \\
0.275 & $46.6 \%$ & 0.259 & 0.344 & 74 & -26 & -31 \\
0.250 & $47.7 \%$ & 0.261 & 0.347 & 75 & -27 & -30 \\
0.225 & $49.3 \%$ & 0.265 & 0.350 & 76 & -26 & -29 \\
0.200 & $51.4 \%$ & 0.270 & 0.354 & 77 & -26 & -27 \\
0.175 & $54.7 \%$ & 0.278 & 0.360 & 79 & -25 & -24 \\
0.150 & $60.3 \%$ & 0.292 & 0.368 & 82 & -22 & -19 \\
0.125 & $77.5 \%$ & 0.334 & 0.384 & 91 & -10 & -6 \\
0.100 & $82.1 \%$ & 0.343 & 0.386 & 93 & -7 & -3 \\
0.075 & $84.1 \%$ & 0.347 & 0.386 & 93 & -5 & -2 \\
0.050 & $85.4 \%$ & 0.349 & 0.387 & 94 & -5 & -1 \\
0.025 & $86.1 \%$ & 0.352 & 0.387 & 94 & -3 & -1 \\
0.000 & $87.4 \%$ & 0.353 & 0.387 & 95 & -3 & 0 \\
-0.050 & $89.4 \%$ & 0.356 & 0.387 & 96 & -2 & 0 \\
-0.100 & $90.7 \%$ & 0.357 & 0.387 & 96 & -1 & 1 \\
$\mathbf{- 0 . 2 0 0}$ & $\mathbf{9 1 . 4 \%}$ & $\mathbf{0 . 3 5 9}$ & $\mathbf{0 . 3 8 6}$ & $\mathbf{9 7}$ & $\mathbf{0}$ & $\mathbf{1}$ \\
\hline
\end{tabular}


Table 2 Coordinates for oxidation of PB to PY as a film on an ITO/glass substrate in aqueous $0.2 \mathrm{M} \mathrm{KCl}$ supporting electrolyte

\begin{tabular}{ccccccc}
\hline $\begin{array}{c}\text { E/V vs. } \\
\text { Ag/AgCl }\end{array}$ & $\mathbf{\%} \boldsymbol{Y}$ & $\boldsymbol{x}$ & $\boldsymbol{y}$ & $\boldsymbol{L}^{*}$ & $\boldsymbol{a}^{*}$ & $\boldsymbol{b}^{*}$ \\
\hline 0.500 & $47.3 \%$ & 0.263 & 0.346 & 74 & -25 & -30 \\
0.850 & $65.9 \%$ & 0.337 & 0.402 & 85 & -15 & 2 \\
0.900 & $71.9 \%$ & 0.359 & 0.409 & 88 & -9 & 9 \\
1.000 & $77.4 \%$ & 0.375 & 0.412 & 91 & -3 & 15 \\
1.100 & $82.2 \%$ & 0.385 & 0.412 & 93 & 1 & 18 \\
1.200 & $84.2 \%$ & 0.386 & 0.410 & 94 & 2 & 18 \\
\hline
\end{tabular}


Table 3 Optical and electrochemical data collected for coloration efficiency measurements

\begin{tabular}{|c|c|c|c|c|c|c|}
\hline & $\begin{array}{l}\text { \% of } \\
\text { full } \\
\text { switch }\end{array}$ & $\Delta \% T$ & $\Delta A$ & $Q / \mathrm{mC} \mathrm{cm}^{-2}$ & $\eta / \mathrm{cm}^{2} \mathrm{C}^{-1}$ & $t / \mathrm{s}$ \\
\hline $\mathrm{PB} / \mathrm{PW}$ & 90 & 53.8 & 0.673 & 4.49 & 150 & 3.4 \\
\hline PB/PW & 95 & 56.6 & 0.691 & 4.85 & 143 & 4.4 \\
\hline $\mathrm{PB} / \mathrm{PW}$ & 98 & 58.3 & 0.701 & 5.18 & 135 & 6.0 \\
\hline $\mathrm{PW} / \mathrm{PB}$ & 90 & 52.9 & 0.564 & 3.85 & 147 & 1.9 \\
\hline PW/PB & 95 & 55.9 & 0.632 & 4.21 & 150 & 2.2 \\
\hline $\mathrm{PW} / \mathrm{PB}$ & 98 & 57.5 & 0.675 & 4.54 & 149 & 2.6 \\
\hline PEDOT* & 90 & 48 & 0.48 & 2.49 & 192 & 0.33 \\
\hline PEDOT* & 95 & 51 & 0.49 & 2.68 & 183 & 0.36 \\
\hline PEDOT* & 98 & 53 & 0.50 & 3.04 & 165 & 0.45 \\
\hline
\end{tabular}

*Data from reference (34) 
Figure captions

Fig. 1

Cyclic voltammogram at $5 \mathrm{mV} \mathrm{s}^{-1}$ scan rate for a PB/ITO/glass electrode in aqueous 0.2 $\mathrm{M} \mathrm{KCl}$ supporting electrolyte, showing the voltammetric wave for the $\mathrm{PB} / \mathrm{PW}$ redox switch. Initial potential, $+0.50 \mathrm{~V} v s$. Ag/AgCl. Arrows indicate direction of potential scan.

Fig. 2

Visible/NIR region in situ absorption spectra for a PB/ITO/glass electrode in aqueous 0.2 $\mathrm{M} \mathrm{KCl}$ supporting electrolyte at $+0.50 \mathrm{~V}$ (curve (a) for the PB redox state) and $-0.20 \mathrm{~V}$ (curve (b) for the PW redox state), respectively.

Fig. 3

CIE $1931 x y$ chromaticity diagrams for a PB/ITO/glass electrode in aqueous $0.2 \mathrm{M} \mathrm{KCl}$ supporting electrolyte. The potential ( $v s . \mathrm{Ag} / \mathrm{AgCl}$ ) was decreased, in the steps indicated in Table 1, from the coloured PB $(+0.50 \mathrm{~V})$ to the transparent PW $(-0.20 \mathrm{~V})$ redox states. In Fig. 3(b), the $x y$ coordinates are plotted onto a diagram that shows the locus coordinates, with labelled hue wavelengths, and the evaluation of the dominant wavelength $(488 \mathrm{~nm})$ of the PB redox state.

Fig. 4

CIE $1931 x y$ chromaticity diagrams for a PB/ITO/glass electrode in aqueous $0.2 \mathrm{M} \mathrm{KCl}$ supporting electrolyte. The potential ( $E / \mathrm{V} v s$. $\mathrm{Ag} / \mathrm{AgCl})$ was increased, in the same steps as for Fig. 3, from the transparent PW $(-0.20 \mathrm{~V})$ to the coloured PB $(+0.50 \mathrm{~V})$ redox states. In Fig. 4(b), the $x y$ coordinates are plotted onto a diagram that shows the locus coordinates, with labelled hue wavelengths, and the evaluation of the dominant wavelength $(488 \mathrm{~nm})$ of the PB redox state. 
Fig. 5

Relative luminance (\%), vs. applied potential (E/V vs. Ag/AgCl), for a PB/ITO/glass electrode in aqueous $0.2 \mathrm{M} \mathrm{KCl}$ supporting electrolyte. The potential was decreased (a) and then increased (b), in the same steps as for Figs. 3 and 4, between the coloured PB $(+0.50 \mathrm{~V})$ and the transparent PW $(-0.20 \mathrm{~V})$ redox states.

Fig. 6

Cyclic voltammogram at $10 \mathrm{mV} \mathrm{s}^{-1}$ scan rate for a PB/ITO/glass electrode in aqueous 0.2 $\mathrm{M} \mathrm{KCl}$ supporting electrolyte, showing the voltammetric waves for both the PB/PW and $\mathrm{PB} / \mathrm{PY}$ redox switches. Initial potential $+0.50 \mathrm{~V}$ vs. Ag/AgCl. Arrows indicate direction of potential scan.

Fig. 7

Tandem chronoabsorptometric (a) and chronocoulometric (b) data for a PB/ITO/glass electrode in aqueous $0.2 \mathrm{M} \mathrm{KCl}$ supporting electrolyte, on square-wave switching between $+0.50 \mathrm{~V}$ (PB, high absorbance) and $-0.20 \mathrm{~V}$ (PW, low absorbance) vs. Ag/AgCl. 
Figure 1

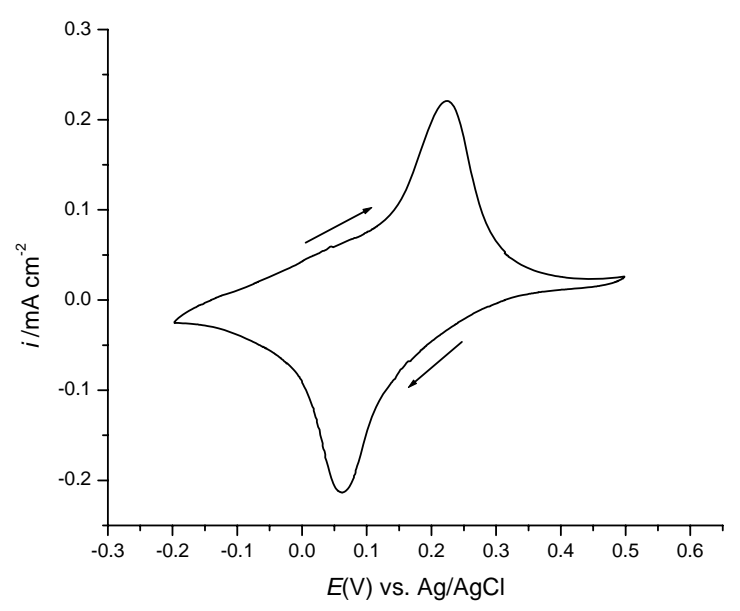


Figure 2

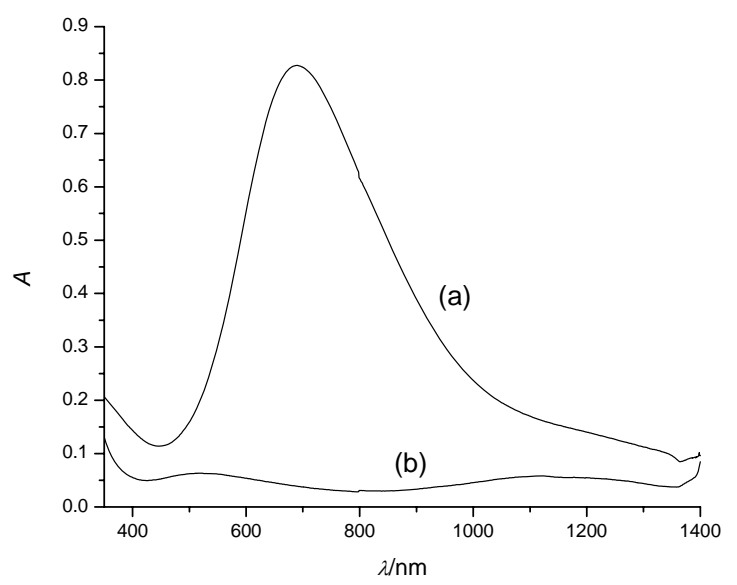


Figure 3
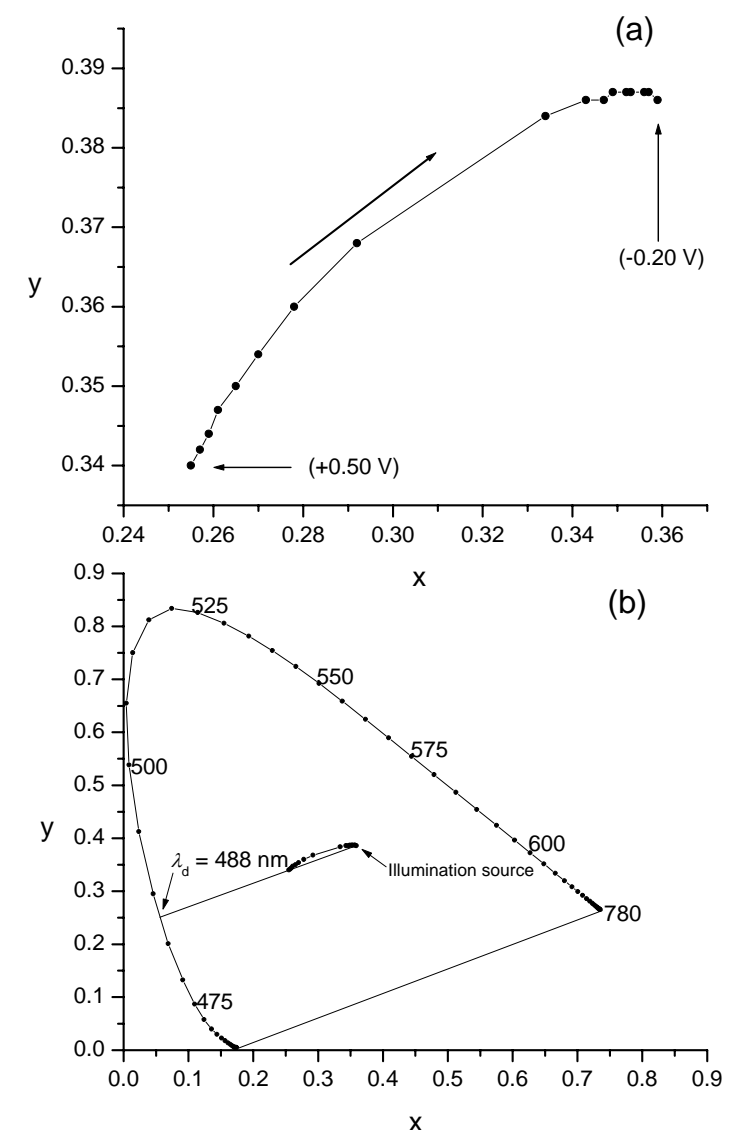
Figure 4
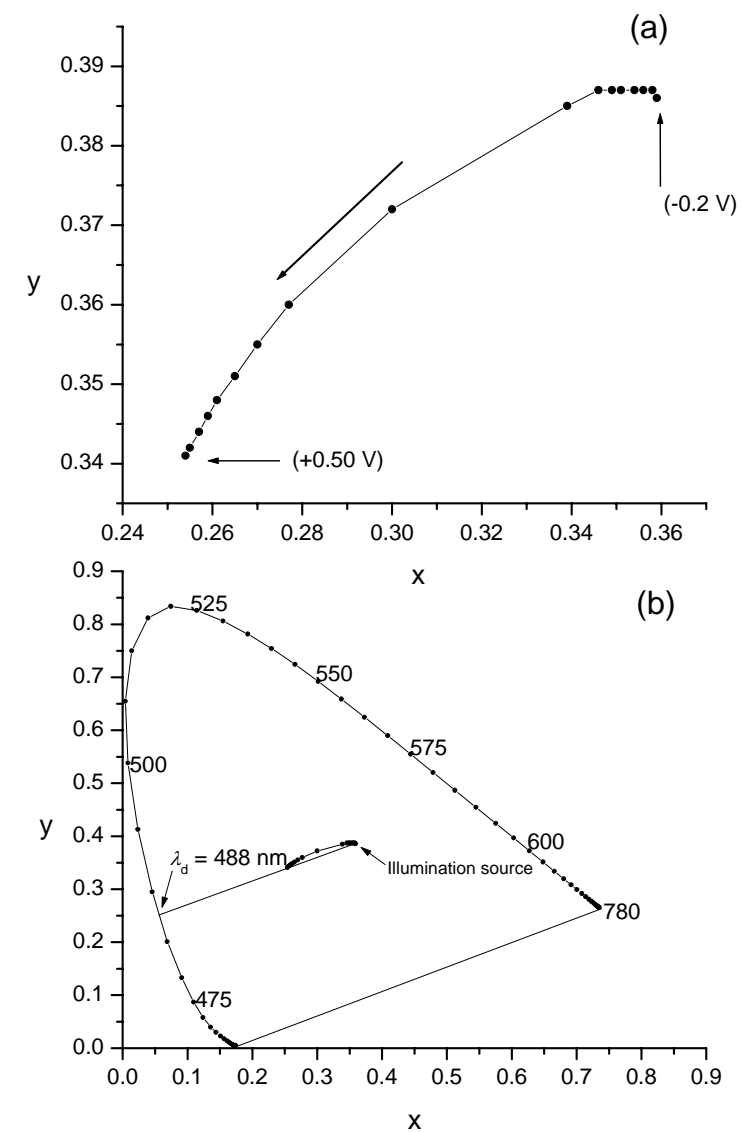
Figure 5

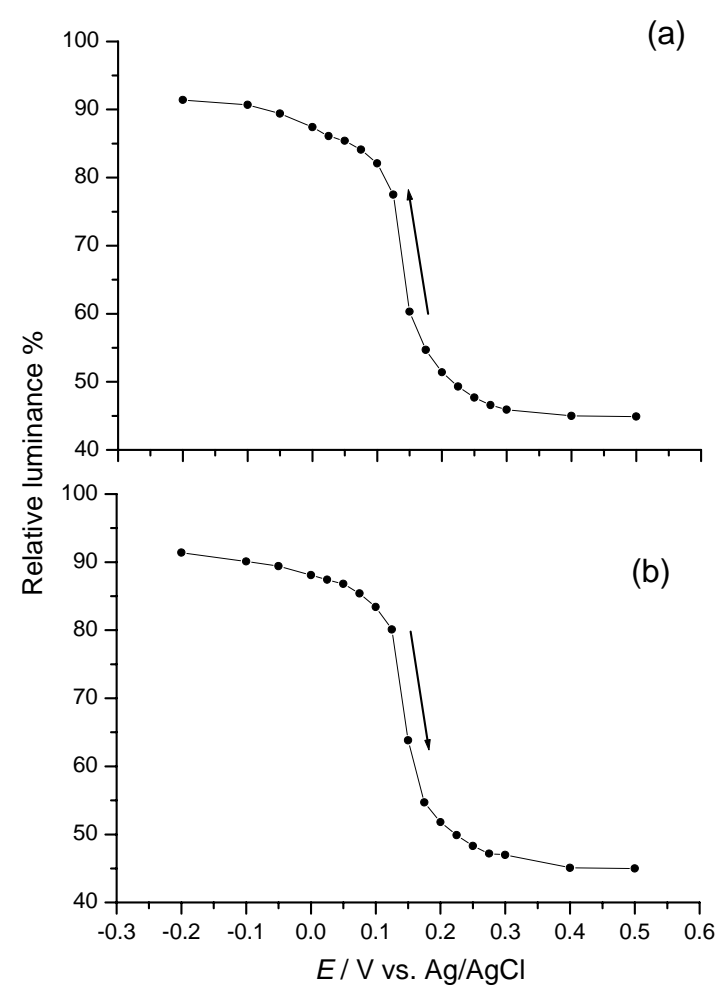


Figure 6

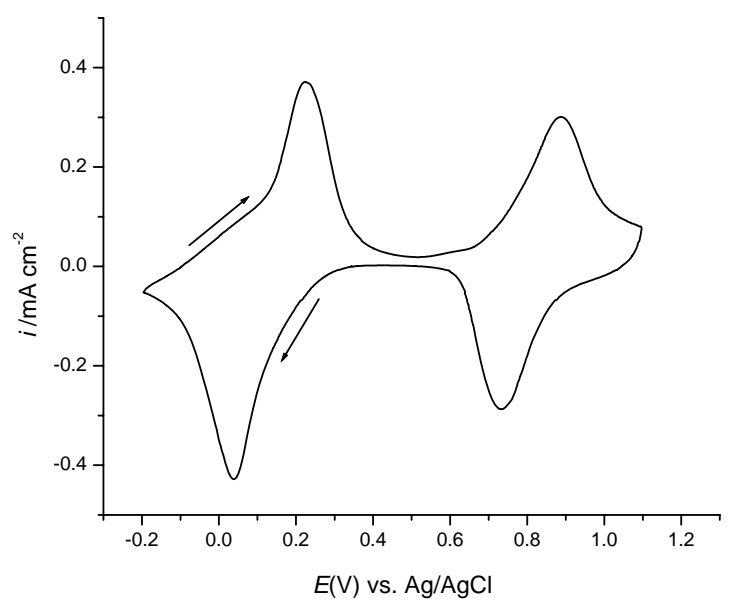


Figures 7
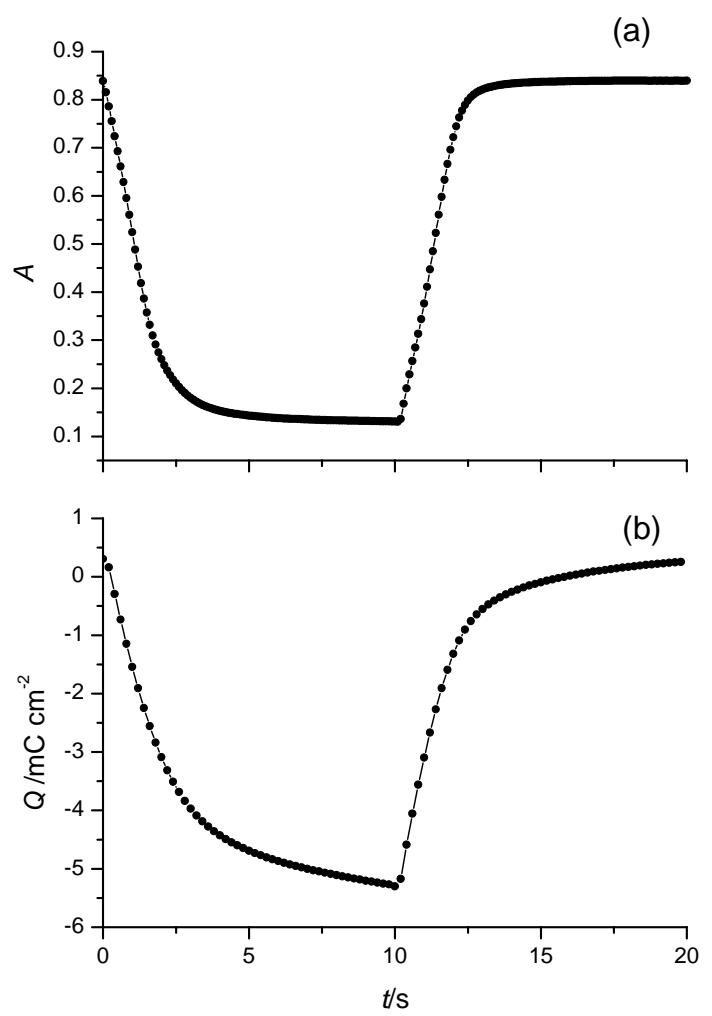


\section{References}

${ }^{1}$ Diesbach (1704) cited in Gmelin, Handbuch der Anorganischen Chemie, vol. 59, Teil B.

${ }^{2}$ K. Fukuda, in Pigment Handbook, ed. P. A. Lewis, vol. I, 2nd. ed., Wiley Interscience, New York, 1988, pp. 357-365.

${ }^{3}$ Colour Index 3rd. ed., vol. 4, Society of Dyers and Colourists, Bradford, England, 1971, p. 4673.

${ }^{4}$ K. R. Dunbar and R. A. Heintz, ed. K. D. Karlin, Progress in Inorganic Chemistry, J. Wiley, New York, 1997, pp. 283-391.

${ }^{5}$ K. Itaya, I. Uchida and V. D. Neff, Acc. Chem. Res., 1986, 19, 162.

${ }^{6}$ V. D. Neff, J. Electrochem. Soc., 1978, 125, 886.

${ }^{7}$ P. M. S. Monk, R. J. Mortimer and D. R. Rosseinsky, Electrochromism: Fundamentals and Applications, VCH, Weinheim, 1995, ch. 6.

${ }^{8}$ F. Li and S. Dong, Electrochim. Acta, 1987, 32, 1511.

${ }^{9}$ S. Dong and G. Che, J. Electroanal. Chem., 1991, 315, 191.

${ }^{10}$ J. A. Cox, R. K. Jaworski and P. J. Kulesza, Electroanalysis, 1991, 3, 869.

${ }^{11}$ A. A. Karyakin, Electroanalysis, 2001, 13, 813.

${ }^{12}$ R. Koncki, Crit. Rev. Anal. Chem., 2002, 32, 79.

${ }^{13}$ R.J. Mortimer and D.R. Rosseinsky, J. Electroanal. Chem., 1983, 151, 133.

${ }^{14}$ R.J. Mortimer and D.R. Rosseinsky, J. Chem. Soc. Dalton Trans., 19842059.

${ }^{15}$ K. Itaya, K. Shibayama, H. Akahoshi and S. Toshima, J. Appl. Phys., 1982, 53, 804.

${ }^{16}$ K. Honda, J. Ochiai and H. Hayashi, J. Chem. Soc., Chem. Commun., 1986, 168.

${ }^{17}$ K. Honda and A. Kuwano, J. Electrochem. Soc., 1986, 133, 853. 
${ }^{18}$ M. K. Carpenter and R. S. Conell, J. Electrochem. Soc., 1990, 137, 2464.

${ }^{19}$ K. Honda, M. Fujita, H. Ishida, R. Yamamoto and K. Ohgaki, J. Electrochem. Soc., 1988, 135, 3151.

${ }^{20}$ M. A. Habib, S. P. Maheswari and M. K. Carpenter, J. Appl. Electrochem., 1991, 21, 203.

${ }^{21}$ M. A. Habib and S. P. Maheswari, J. Electrochem. Soc., 1992, 139, 2155.

22 J-G. Béraud and D. Deroo, Solar Energy Mater. Solar Cells, 1993, 31, 263.

${ }^{23}$ K-C. Ho, Electrochim. Acta, 1999, 44, 3227.

${ }^{24}$ E. A. R. Duek, M-A. De Paoli and M. Mastragostino, Adv. Mater., 1992, 4, 287.

${ }^{25}$ E. A. R. Duek, M-A. De Paoli and M. Mastragostino, Adv. Mater., 1993, 5, 650.

${ }^{26}$ M. Morita, J. Appl. Poly. Sci., 1994, 52, 711.

${ }^{27}$ B. P. Jelle, G. Hagen and S. Nodland, Electrochim. Acta, 1993, 38, 1497.

${ }^{28}$ B. P. Jelle and G. Hagen, J. Electrochem. Soc., 1993, 140, 3560.

${ }^{29}$ N. Leventis and Y. C. Chung, J. Electrochem. Soc., 1990, 137, 3321.

${ }^{30}$ B. P. Jelle and G. Hagen, J. Appl. Electrochem., 1999, 29, 1103.

${ }^{31}$ N. Kashiwazaki, Solar Energy Mater. Solar Cells, 1992, 25, 349.

${ }^{32}$ T-S. Tung and K-C. Ho, Abstract No. 1313. 203rd Electrochemical Society Meeting, Paris, France, 27 April - 2 May, 2003. Meeting Abstracts, Volume 2003-01.

Electrochromics Materials and Applications Symposium, (Symposium Organisers: A. Rougier, D. Rauh, G. A. Nazri and G. Hunter).

${ }^{33}$ B. C. Thompson, P. Schottland, K. Zong and J. R. Reynolds, Chem. Mater., 2000, 12, 1563. 
${ }^{34}$ C. L. Gaupp, D. M. Welsh, R. D. Rauh and J. R. Reynolds, Chem. Mater., 2002, 14, 3964.

${ }^{35}$ G. Wyszecki and W. S. Stiles, Color Science: Concepts and Methods, Quantitative Data and Formulae, J. Wiley \& Sons, New York, $2^{\text {nd }}$ Edition, 1982.

${ }^{36}$ B. C. Thompson, P. Scottland, G. Sönmez and J. R. Reynolds, Synth. Met., 2001, 119, 333.

${ }^{37}$ I. Schwendeman, R. Hickman, G. Sönmez, P. Schottland, K. Zong, D. M. Welsh and J. R. Reynolds, Chem. Mater., 2002, 14, 3118.

${ }^{38}$ G. Sönmez, I. Schwendeman, P. Schottland, K. Zong and J. R. Reynolds, Macromolecules, 2003, 36, 639.

${ }^{39}$ A. Cirpan, A. A. Argun, C. R. G. Grenier, B. D. Reeves and J. R. Reynolds, J. Mater. Chem., 2003, 13, 2422.

${ }^{40}$ G. Sönmez, H. Meng and F Wudl, Chem. Mater., 2004, 16, 574.

${ }^{41}$ C. A. Thomas, K. Zong, K. A. Abboud, P. J. Steel and J. R. Reynolds, J. Am. Chem. Soc., 2004, in press.

${ }^{42}$ T. Furuta, T. Shimomura, H. Mada and S. Kobayashi, Jap. J. Appl. Phys., Part 2: Letters, 1981, 20, L768.

${ }^{43}$ T. Shimomura, T. Furata and T. Maki, Jap. J. Appl. Phys., Part 2: Letters, 1987, 26, L299.

${ }^{44}$ T. Shimomura, T. Furata and Y. Eguchi, Jap. J. Appl. Phys., Part 2: Letters, 1988, 27, L1137.

${ }^{45}$ R. D. Rauh, F. Wang, J. R. Reynolds and D. L. Meeker, Electrochim. Acta, 2001, 46, 2023. 
${ }^{46}$ R. J. Mortimer, J. Electroanal. Chem., 1995, 397, 79.

${ }^{47}$ D. R. Rosseinsky and A. Glidle, J. Electrochem. Soc., 2003, 150, C641.

${ }^{48}$ D. R. Rosseinsky, L. Glasser and H. D. B. Jenkins, J. Am. Chem. Soc., 2004, 126, 10472.

${ }^{49}$ R. T. Marcus, in Color for Science, Art, and Technology, ed. K. Nassau, Elsevier, Amsterdam, 1998, pp. 31-96.

${ }^{50}$ M. Ertas and J. R. Reynolds, unpublished results.

${ }^{51}$ K. Itaya, N. Shoji and I. Uchida, J. Am. Chem. Soc., 1984, 106, 3423.

${ }^{52}$ S. Lupu, C. Mihailciuc, L. Pigani, R. Seeber, N. Totir and C. Zanardi, Electrochem. Commun., 2002, 4, 753.

${ }^{53}$ P-H. Aubert, A. A. Argun, A. Cirpan, D. B. Tanner and J. R. Reynolds, Chem. Mater., 2004, 16, 2386.

${ }^{54}$ A. A. Argun, P-H. Aubert, B. C. Thompson, I. Scwendeman, C. L. Gaupp, J. Hwang, N. J. Pinto, D. B. Tanner, A. G. MacDiarmid and J. R. Reynolds, Chem. Mater., 2004, 23, 4401.

${ }^{55}$ B. D. Reeves, C. R. G. Grenier, A. A. Argun, A. Cirpan, T. D. McCarley and J. R. Reynolds, Macromolecules, 2004, 37, 7559. 